\title{
What is interaction science? Revisiting the aims and scope of JolS
}

\author{
Gisela Susanne Bahr ${ }^{1}$ and Christian Stary ${ }^{2^{*}}$
}

\begin{abstract}
Interaction Science has undergone rapid development since JoIS' (the Journal of Interaction Science) founding in 2013. The advent of novel techniques and tools required reviewing the understanding of Interaction Science and the scope and aims of JolS. More particularly, the set of methods and frameworks needed to be revisited and checked against the characteristics of today's ecological system and the resulting requirements for developing socio-technical systems. In this editorial, we tackle the interdisciplinary nature of Human-Computer-Interaction, the different thematic areas in Interaction Science, and diverse scientific research methods (and methodologies). We also examine the JolS articles published so far, in order to provide a sound baseline for re-defining Interaction Science and update the mission of JolS accordingly. The newly proposed definition of Interaction Science explicitly takes into account diversity and transdisciplinarity of interactional phenomena. We recognize the action space of Interaction Science being complex and ever-changing, and thus opt for wide generalization. Such way, the interaction is considered as the exchange of material or immaterial goods between acting parties (biological or technical entities) embodied in a certain context. Regarding scientific methodology, one of the important proposals relevant to JolS is to relax emphasize on the use of empirical investigation based on traditional laboratory experiment. Traditional laboratory empiricism (usually empowered by statistics and hypothesis testing) is too restrictive to exclusively represent JoIS' aims and scope, so we make way to complementary methods such as modeling, simulation, case studies, and design as science. By acknowledging studies of new methodologies, metrics and measurements, as well as work grounded in theories and applications, we ask for future contributors to stay committed to the TEAM (Theory advancement, Empirical advancement, Applied advancement, Methodological advancements) approach. We finally anticipate for the next decade Interaction Science will progressively integrate its scientific concerns with the engineering goal of improving the interactive design of socio-technical systems, resulting in a body of transdisciplinary knowledge and methodology. Interaction Science continues to provide a challenging test domain for applying and developing psychological and social theory in the context of technology development and use.
\end{abstract}

Keywords: Editorial, Interaction Science, Human-Computer Interaction, Interaction, Science, Design, Socio-technical systems, Design Science, System-of-Systems

\section{Introduction}

When the Journal of interaction Science started, the founding editor-in-chief, Gisela Susanne Bahr, wrote in the inaugural editorial ${ }^{1}$.

"... JoIS is grounded in empiricism and employs the best of psychology, its experimental methodology and statistics. We believe that rigorous research methodology is the marlin spike that can unravel the convoluted knot

\footnotetext{
* Correspondence: christian.stary@jku.at

${ }^{2}$ University of Linz, Altenbergerstraße 69, 4040 Linz, Austria

Full list of author information is available at the end of the article
}

of interactions between humans and the technologies that they have created. Our goal is to attract and publish scientific investigations of human interactions with modern technologies, including their potential for bringing about change, their limitations, their benefits, their consequences and their broader impact.

It follows that the definition of what we do is in the papers we publish: JoIS and its authors advance interaction science using the TEAM approach: Theory advancement, Empirical advancement, Applied advancement, Methodological advancements." 
When Chris Stary joined JoIS as co-editor in chief one of the conversation topics of the editorial team has been whether experimental empiricism is too restrictive to represent JoIS' aims and scope. Should JoIS be more inclusive of other ways to conduct scientific investigations and relax the emphasis on the use of traditional laboratory experiments? The two editors decided to put the editorial to the test and evaluate the statement, "the definition of what we do is in the papers we publish." The challenge is whether they can agree on a definition for Interaction Science based on the JoIS publications to date. In the end, our different perspectives converge on a shared vision and the answer is "yes".

The discussion has been influenced by recent contributions in the field of Human Computer Interaction (HCI). For example, Howes et al. [1] address the role of science in $\mathrm{HCI}$, and state that scientific contributions in the field of HCI have been partially informed by techniques and findings from the behavioral sciences and computer science. Their observation conveys the interdisciplinary nature of Interaction Sciences and hints to the emerging complexity. With this in mind, several challenges emerge. For example, how can we satisfy the necessity to structure the diverse field of Interaction Science studies? Moreover, what is the relation between science and design? Designing and prototyping studies make creative and technical assumptions that fall outside the scope of laboratory study. Hence, 'the imperative for "design implications" can mediate against scientific values and against high risk work on hard problems.' (ibid., p. 1129). One might conceptualize the imperative for design implications as a non-empirical way to reduce the degrees of freedom when solving a complex problem, such as designing interaction solutions for computer assisted design or emotive health-care robots.

The implications of design decisions are not trivial but shape and determine products; however, they are necessary because the empirical investigation of every variable at every possible value is impossible. The concept of the design decision is not a modern term but traceable through the centuries. For example, Johannes Gutenberg has been credited for making design decisions as well as technical innovations that led to variations in the composition, presswork and decoration evident in the surviving paper and vellum Gutenberg bibles (http://www.themorgan.org/ collection/Gutenberg-Bible). Imagine a classic laboratory study that requires four independent variables each with two, three, two and four levels respectively, on an unknown number of dependent variables (metrics).

A sample experiment with such a factorial design might be an HCI study comparing expert and novice users (factor 1) using touch, auditory or visual interfaces (factor 2), performing task of high or low difficulty (factor 3) and receiving one of four types of user feedback (factor 4). The feedback option may be none, same modality as the interface condition, and two incongruent types of feedback selected from auditory, visual or haptic feedback. Regardless of a between- or within-subjects design, the rule of thumb without power analysis is that 25-30 participants per condition are needed to reveal significant effects.

The design described involves 48 conditions, which requires $(48 * 25)=1200$ participants in a pure betweensubjects design. Alternatively, the study could employ $2 * 25=50$ participants if factors $2,3,4$ are changed to within-subjects variables. In the within-subjects scenario, each participant performs 2 tasks on 3 different interfaces, 4 times to change the type of feedback. Hence, each session consists of 24 tasks per participant. This points to the limitations of within-subjects designs, including cross-contamination of conditions, transfer, learning and fatigue affects, which may be somewhat ameliorated by counterbalancing. It remains to reason how many participants are necessary to effectively counterbalance and analyze for the occurrence of time based trends and ordering effects based on 24 tasks. It is easy to see that the complexity of what appears to be a conceptually reasonable study design is experimentally not feasible.

As a consequence of complexity, the need for research methodologies in addition to the classic laboratory experiment becomes apparent. Without relaxing the rigor of scientific investigation, an alternative method common in design sciences is the case study. This approach can provide insight to complex situations and highly specialized user groups that are not accessible, transferable or translatable to laboratory settings and the experimenter controlled independent variables.

\section{Mindful of the need for the confluence of empiricism and design in Interaction Science, the goal of this paper is to build bridges between the rigor of empirical investigations and design-centered engineering approaches under an explanatory and inclusive umbrella of Interaction Science} This paper is intended to serve as new editorial guidance to upcoming and future work in Interaction Science. The purpose of this editorial is to introduce JoIS readers and JoIS authors to the journal's editorial diversity and the definition of Interaction Science with the goal to update the vision of JoIS and its aims and scope. Thereby, Interaction Science is described by a breadth of different thematic areas that are not necessarily linked to a single research domain.

Research listed in Table 1 may be conducted in social and cognitive sciences, biomedical engineering, life science, artificial intelligence research, usability engineering, design engineering, industrial design, occupational science, mechatronics, and of course, computer science. 
Table 1 Research relevant to Interaction Science

Examples of related research to Interaction Science

Novel interface paradigms and technologies, e.g., haptics, gestures, vision and brain computer interfaces

Development of innovative technologies in specific domains, e.g., medical apps or healthcare informatics

Wearable and mobile analytics, e.g., interaction rates for smartphone data entry

Studies of different user populations, e.g., people with disabilities or older adults

Effects of technologically mediated interactions on perception and cognition, e.g. human memory, cognitive development, decision making, problem solving and creativity

Interaction paradigm shifts in educational, business, government, military contexts and the arts, e.g., as online learning, financial advising bots, paperless admin, network-centric operations, interactive multi-media art

Privacy and security of the incidental collection of interaction data, e.g., during web-based activities

Effects of the increasing diffusion of technology into social systems

Without elaborating our initial definition of Interaction Science, i.e., "science of interactions between humans and the technologies that they have created", the resulting diversity of research may seem confusing and randomly assembled. To develop and contextualize this definition, we begin by exploring and defining the terms "interaction" and "science" in sections 2 and 3. This is followed by an analysis of the approaches, access and topics of the JoIS papers published to date. Lastly in section 4 , and most importantly, we present our definition of Interaction Science" and our 2016 vision for JoIS in sections 5 and 6 , before concluding the editorial in section 7 .

\section{What is interaction?}

In this section the concept of interaction is discussed according to recent frameworks and perspectives referring to humans and their engagement in interfacing technology. We address the dynamic nature of systems, leading to recognize socio-technical systems as complex adaptive systems. Taking the system (-of-Systems) perspective, the underlying concepts and theories how scientists view and investigate interaction can be reviewed accordingly. In addition, the role of systems engineers and developers as intermediaries between users and technologies can be recognized explicitly.

In general, the term interaction implies some form of relationship between or among entities. In the context of the JoIS the entities are either biological systems or technological artefacts. Biological systems may be humans in general, specific populations or perhaps individuals. Technological artefacts may be some computational systems that are external or internal to an entity and support some form of active or passive behavior and exchanges.

Overtime, these interactions establish behavioral and cognitive schemas that transfer as patterns and expectations to further activities and in this way influence the acting stakeholders. Stakeholders are identified as the persons that are involved in system- and interactionrelevant processes, either operating, (re-)design, monitoring or controlling a system. As they interact in a certain environment, they create specific patterns in the system representing the environment. These patterns are termed system-wide patterns. According to the theory of Complex Adaptive Systems (see Fig. 1) the patterns shape the behavior of each agent (humans, robots, software applications etc.,) in this system, thus, determining, the way, each entity of this system interact. The advent of innovative applications, such as SMS-services and the resulting communication behavior of mobile-device users in terms of creating communication symbols and frequency of interaction, demonstrates these mutual dependencies in an ostensive way.

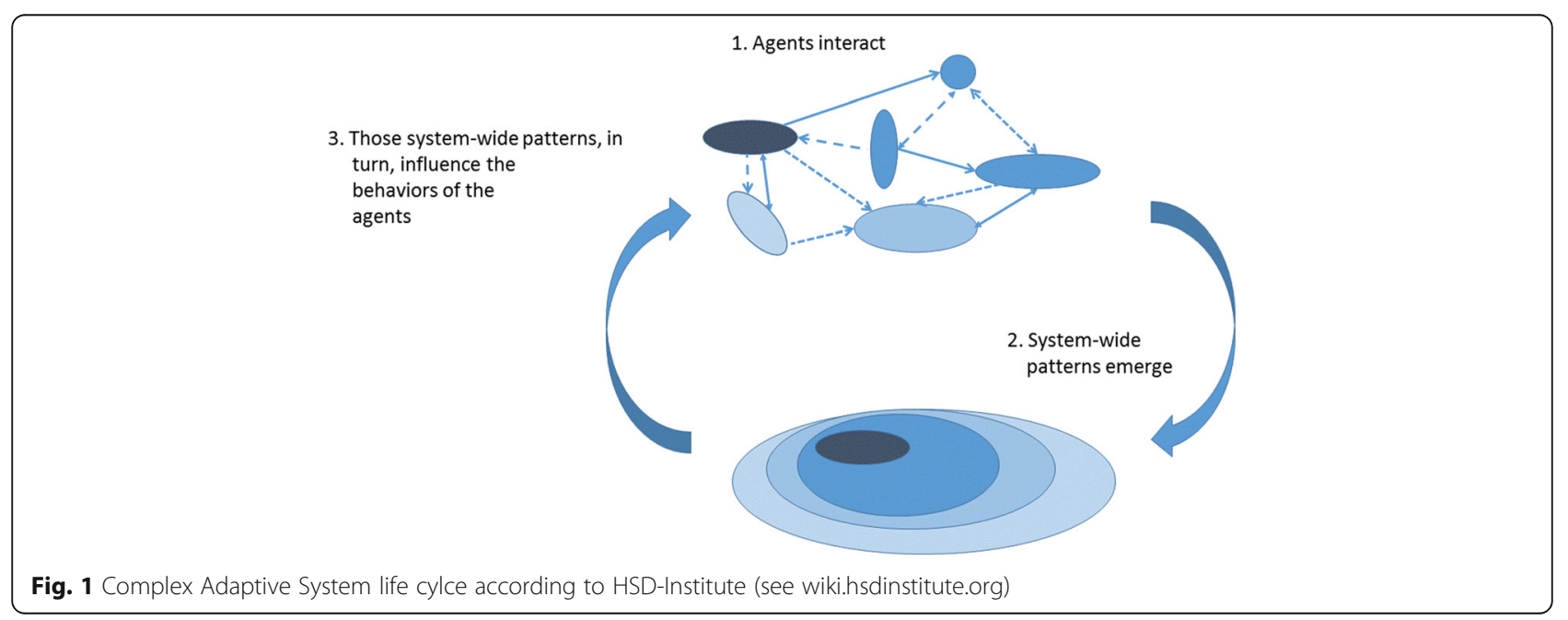


Social, socio-technical, technical and system-to-system interactions

Given the continuous spread and connectedness of societal systems, such as economic systems, communication and technologies across the world, the complexity and size of the systems involved, the speed of communication, the exchanges between humans as well as the changes affecting individual persons have increased interactions dramatically. They concern both, passive (through the consumer role), and active discourse (through the provider role) (cf [2]).

Stakeholders increasingly operate and interact in highly dynamic and volatile environments, due to a variety of factors, in particular due to the increase of economization of society [3], accompanied by the increasing penetration of technology in various societal systems (cf [4]). Accordingly, socio-technical systems are part of other systems where stakeholders interact in their environment. These systems are socio-ecological systems (cf. $[5,6])$ including economic systems, again humans in the role of providers (e.g., producer of services and goods), and consumers (e.g., stakeholders getting informed on production methods) - see also Fig. 2. In these systems, social relations are of equal importance as the exchange of information or goods achieving (economic) objectives, as they allow stakeholders to act locally while collaborating globally (cf. [7]).

Consequently, interaction is a multi-facet phenomenon that needs to be studied from a variety of perspectives and levels of analysis and transparencies. When communication and interaction occurs increasingly electronically and in virtual settings, due to global work distribution and social media diffusion, the technological infrastructure has to be highly reliable and adaptable performing - the infrastructure has to take into account the complexity and high dynamics of socio-technical systems. Designing those systems requires respective concepts, such as adaptive governance (cf [6]).

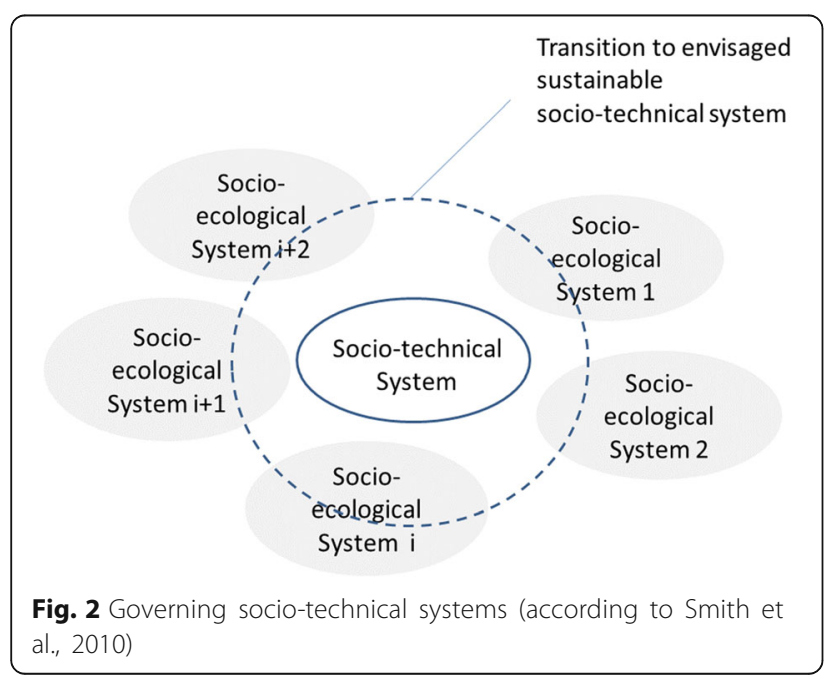

Recent technological developments, such as cyberphysical systems, revealed the importance of systemto-system interaction on the technical or device level (cf [8]). For instance, Internet-of-Things application development has to deal with latency, power limitation, reliability (unreliability), network topology related effects as well as data processing. Once unification approaches or standards become too complex, smaller particles of applications, such as micro-services come into play (cf [9]). They allow composing architecture patterns as a set of small independent, but coordinated processes [10]. Services communicate with some lightweight protocols [11], in order to deploy micro-services, such as navigation or data updates, independently.

The management of these services becomes a challenging task, once it is also considered a separate service. Hence, designing technological artefacts has to be considered as a task of allocating micro-services to achieve a certain objective: an example is Open IoT [12], which supports coupling additional elements and modules on demand due to known interfaces and data formats. Again, skillful interaction brings stakeholders closer to design tasks, in particular in additive manufacturing, which enables networked citizens to produce their own goods having provided with respective digital literacy and modeling skills (cf [13]). Another domain, namely healthcare, has been explored utilizing micro-services recently, such as intelligent sensing of a patient's blood pressure (cf [14]). Toolkits can provide modularization and extensibility on different levels, leading to micro-services for small, systemwide features based on a service-oriented architecture.

Recognizing the current situation and anticipating further system developments,

\section{Interaction has to be considered as the exchange of material or immaterial goods between acting parties (biological or technical entities) embodied in a certain context.}

Interaction occurs along transactions between entities. From a system perspective these entities are elements or system components that are mutually linked through exchange relationships, and are part of a discourse in the encompassing system.

Having explored, contextualized and defined our conceptualization of interaction, our understanding of what constitutes scientific research and the role of scientific methodology are presented next.

\section{What is science?}

According the Merriam Webster dictionary "science" is described as knowledge about or the study of the natural world based on facts learned through experiments and observation. This definition appears deceptively simple 
and yet it implicitly invokes a complex concept, epistemology $^{3}$ (ways of knowing or how to discover knowledge). Overall, a particular approach to epistemology is paramount in the scientific community: empiricism ${ }^{4}$. Other epistemological approaches such as rationalism ${ }^{5}$ or skepticism have less influence in the sciences and play a greater role in philosophy or domains that defy observation and experimentation. Empiricism differs from rationalism or skepticism in that it requires the interaction of the investigator with the physical world, using research methodologies to collect observations and to test hypotheses. Karl Popper further developed scientific empiricism by logically improving hypothesis testing as a process whose outcomes include the possibility that a theory may be false (falsifiability ${ }^{6}$ ). His contribution simplifies to the practice of scientists not seeking to confirm their hypotheses but instead hoping to reject the generality of a given null hypothesis.

\section{Science defined by method (and not by topic)}

It is easy to argue that scientific methodologies are at the core of the definition of science where science is a process, an ongoing activity dedicated to the discovery of knowledge. This implies that science is not defined by its topic but science is defined as a process of knowledge discovery. For example, it is possible to conduct unscientific studies in the natural sciences and at the same time one may conduct scientific investigations of artificial phenomena, such as databases, computer hardware or cyber security.

Paramount among empirical methodologies is the experiment. The design of an experiment requires scientists to define groups for comparison, the manipulation variables and measurement, i.e., observations. In general this is accomplished as follows: Scientists present an a priori hypothesis, design an experiment to test the hypothesis comparing some groups or sets of conditions, conduct the experiment by manipulating variables and holding all else constant, then collect data. Next they evaluate, usually statistically, the data and examine whether based on the results they can reject the null hypotheses. These scientists publish, only to make way for the next experiment.

Are there other scientific alternatives that are observation based? In other words, can scientists make scientific observations without conducting a laboratory experiment?

\section{Complementary methods}

Computational power has giving science new ways to investigate natural phenomena and complexity [15]. What escapes traditional experiments because of the number of variables involved or the scope of temporal and physical dimensions can be modelled and simulated (with an acknowledged set of limitations or restraints). The question is whether these approaches are empirical. We as scientists argue that such approaches can be empirical if they generate data based on different assumptions and then test these assumptions. In that sense, modelling and simulation can be viewed from an empirical experimental perspective as a case of model comparisons by manipulating assumptions and then comparing the data generated by different models.

The example of modelling and simulation as experiments provides the first glimpse at alternative approaches that complement the traditional scientific approaches to human technology interactions, which are experimentally based. Another relevant approach that adds context and preserves complexity in interaction research is the case study. The Oxford University Press dictionary presents two definitions ${ }^{7}$ of case studies,

1. a process or record of research in which detailed consideration is given to the development of a particular person, group, or situation over a period of time.

2. A particular instance of something used or analyzed in order to illustrate a thesis or principle, for example "airline deregulation provides a case study of the effects of the internal market."

We are initially concerned with the first definition, given that the alternative definition suggests the use of case study as point-in-case, an example or ad-hoc explanation for a phenomenon. Nevertheless, the conceptualization of the case study as the process or record of research in which detailed consideration is given to the development of a particular person, group, or situation over a period of time, implies an empirical approach of systematic observations that are collected by following the object of study, the case. The flexibility of this definition has given rise to questions about the scientific legitimacy of case studies. Case study research has been criticized for ambiguity, limitation and measurement approaches [16]. Similarly, one might ask, what is the definition of a case? Is it equivalent to a sample? If so, can the case be considered representative so we can generalize to a population? These are provocative questions and they raise the issues of contextualization and ontology research [17] which are central to case study research. A practical example of the role of context is described by [18] in three case study design steps:

"First, we relate to our research problems, selecting the process and/or outcome to be studied. Second, we define the context, the elements that we treat as the environment of the process singled out. Third, we trace the specific links in the process we have selected. Depending on the quality of our knowledge about the case, we arrive at an explanation of the case." 
It becomes apparent that context provides definition and specificity relevant to the study design, which is similar to Geertz's [19] term 'thick description', emphasizing the specific and the contextual and what appears circumstantial to make behavior meaningful to the outsider. Likewise, it appears that the potential contributions of the case study methods to Interaction Science are driven by the inclusion of contextual factors without the need for reductionist methods that fail to reproduce the richness of a situation in the laboratory with a limited number of variables. The case study as such can intervene in an ongoing process in an existing context or attempt to reconstruct both context and process from existing data. While the former support direct observation of the study of object, the latter relies use of existing data and may, depending on the quality of the data require interpretation and some guess work. In that sense it is similar to the alternative definition of case study that we dismissed earlier, but it remains suitable in an ontological analysis to reveal a perspective of the reality investigated. Ultimately, the usefulness of reconstruction is driven by quality and quantity of the available data. In fact, one might argue in an era of increasingly detailed digital footprints, i.e., the trail, traces or "footprints" that people leave online, that reconstruction provides considerable case insight into behavior specific to online contexts. Regardless of the exact nature of the case study approach, or how varied and variable data collection and contextual knowledge are, the inclusion of context in the observation of a naturally observed phenomena for explaining behavior and process, must be considered provocative and valuable. More recently, [20] formalized the idea of case studies inclusion in the domain of design science, engaging both practitioners and scientists. (See Fig. 3 left.) While the figure is self- explanatory, an embedded cycle, either regulating or regulative (translated from the Dutch regulatieve cyclus) requires clarification. It was originally defined by [21] and consists of the five steps (problem definition - diagnosis - plan intervention - evaluation). The purpose of the full reflective cycle is to use a series of cases, reflect on their results and develop design knowledge.

While case studies hardly satisfy Popper's falsifiability criterion, they give rise to varied perspectives and generate possible explanations that extend and contextualize the scope of traditional hypothesis testing and facilitate the generation of rival hypotheses. Indeed, case based explanations are a source of knowledge and may reveal the possibility of causal relationships and unsuspected correlation, which in turn give rise to testable theories. As a result, case study research provides insight to complex phenomena and contribute to the cycle of empirical research [22] (See Fig. 3 right).

\section{Methodologies are part of the TEAM approach}

One can argue that epistemology includes but is not limited to empiricism, hence other approaches in the quest for knowledge discovery can contribute to the purpose of advancing our understanding of natural and technical phenomena. It appears that in addition to the classic laboratory experiments and complementary empirical approaches, scientific discovery requires the development of new methodologies, metrics and measurements, as well as theory and applied work. Hence the domains of method, theory, application development have a place in science and complement empirical studies. These approaches are in line with the original JoIS mission embracing the TEAM (theory, empirical data, application and method) to research. Examples of theoretical contributions are literature reviews, frameworks; it is easy to see that theory challenges scientists to test its scope and validity; at the same time, theory informs and inspires engineers to design and innovate.

Complementary to theoretical investigation are examples of applied work, such as prototype and product development, and case observations; as scientists we may

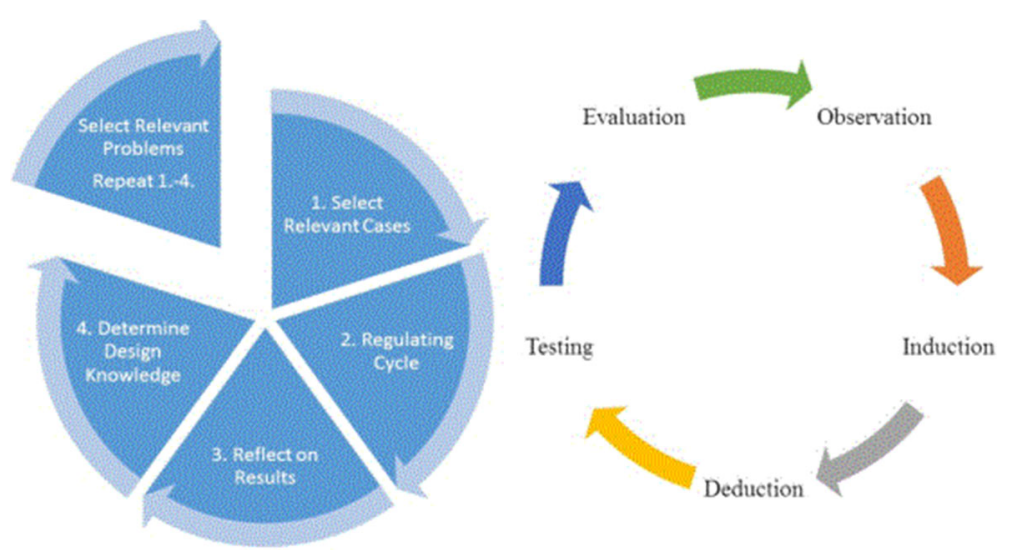

Fig. 3 Aiken's reflective cycle (left); De Groot's empirical cycle (right) 
eschew such research for its lack of incremental progression; as engineers, this work is instrumental for the investigation and testing of approximated solutions to open-ended problems whose complexities defy the laboratory limitations and simulation assumptions. While these applied approaches are exploratory in nature but remain empirical because user testing and measurement of complex artifacts, for example of augmented reality devices like Microsoft's HoloLens or the investigation of click-through activity, generate observable data.

\section{The interplay of complexity and methodology becomes evident in the domain of design science}

McKay et al. [23], in the field of Information Systems, have argued 'for a broader and more integrated view of design: one that emphasizes both the construction-centered and human-centered aspects of design' (p. 125). Hereby, design science can play a crucial role. As user interactions have become more central to socio-technical, in particular with the diffusion of Social Media into application domains and systems, Interaction Science contributions need to capture theorizing about design while expanding the scope from supporting the processes of interaction towards the evolution of socio-technical systems.

Users are not only subjects to be studied in analysis and participate in design, they become the driver of design and development processes. Consequently, design science needs to take a behavior-oriented perspective (cf. [24]), e.g., encapsulating behavior in its interactional context. Such a perspective has been promoted by recent approaches in Business Process Management allowing stakeholders to articulate their behavior and execute the resulting model (cf. [10]). These approaches allow for case-sensitive reflective design not only of individual but rather collective behavior. In times of recognizing diversity as design parameter (cf. [25]), both behaviors are of importance in organizational settings (cf. [26]). From a methodological perspective, the empirical part (evaluation) of designs keeps stakeholders involved they are enabled to test the artefacts they have been generating, and the context of an artefact can be kept throughout the two iterated activities, 'designing an artefact that improves something for stakeholders, and empirically investigating the performance of an artefact in a context' ([27], p. v).

Hereby, Interaction Science as Design science may follow a case-based research or and sample-based research approach:

- 'In case-based research, we study single cases in sequence, drawing conclusions between case studies. This is a well-known approach in the social sciences. In the design sciences, we take the same approach when we test an artifact, draw conclusions, and apply a new test. The conclusions of case-based research typically are stated in terms of the architecture and components of the artifact and explain observed behavior in terms of mechanisms in the artifact and context. From this, we generalize by analogy to the population of similar artifacts.

- In sample-based research, by contrast, we study samples of population elements and make generalizations about the distribution of variables over the population by means of statistical inference from a sample. Both kinds of research are done in design science' (ibid. p. vi).

A corresponding design cycle contains iterations over problem investigation, treatment design, and treatment validation. Different cases may require different effort for analysis, design, and evaluation. Analysis needs to be complemented with the research setup, in order to check whether the research setup supports the inferences. The empirical cycle continues with research execution, using the research setup, and data analysis, using the inferences designed earlier.

According to the findings in Wieringa [27] design science approaches relevant for Interaction Science reveal several patterns:

- Observational case studies help analyzing mechanisms that produce phenomena in certain cases, e.g., technological artefacts trigger a certain consumer behavior. Studies of this type concern either social systems, such as development organizations, or technical systems, such as workflow engines, or socio-technical systems, such as recommender systems.

- Single-case mechanism experiments explore the production of certain phenomena in specific situations (individual cases). They concern social or technical systems or socio-technical ones, or models of these systems. They are studied in the laboratory or in the field. In case of a technical system activities refer to testing, whereas in case of studying a socio-technical system, simulation activities are performed.

- Technical action research refers to studies testing a newly designed artifact in the field getting stakeholders involved.

- Statistical difference-making experiments, targets artifact testing by involving a sample of population elements. The outcome is then compared with the outcome of treating another sample with another artifact. In case of a statistically significant difference, the conditions of the experiment are checked to explain the recognized difference. 
Regardless of the selected setting of an investigation scientific as generalizations about the finding on interactional phenomena play a crucial role. Theories in Interaction Science are subject to both, empirical tests and conceptual assessments. Interaction studies may affect entire societal systems, as recent findings from adapting interfaces to cultural settings and parameters reveal [28]. They enhance 'our capability to describe, explain, and predict phenomena and to design artifacts that can be used to treat problems. We need theories both during empirical research and during design. Conversely, empirical research as well as design may contribute to our theoretical knowledge' ([27], p.viii).

What are the topics and methodologies of our publications? Having established our views on interaction and science, we are obliged to perform the test of the "definition [of Interaction Science] is what we publish." It has become increasingly obvious that interactions occur in a variety of contexts, and thus can be studied in a variety of scenarios and domains. While we originally stressed the classic laboratory experiment, it is easy to see that our publications fall into all four areas of our TEAM definition employing complementary empirical methods, such as user modelling and case studies (see Table 2 for a complete listing of JoIS publications since 2013 including keywords and abstracts.) It appears that empirical studies, user modelling, frameworks and case studies comprise the majority of papers (see Fig. 4). The data to date indicate that next to traditional experiments and classic theoretical framework development, user modelling and case studies are noteworthy epistemological approaches in interaction research published in JoIS.

This diversity of methodologies in the articles published does not necessarily reflect the topics that attract our readers. A more relevant measure to reader interest is the number of accesses of each article. What is the operational definition of access? An access means that the article was accessed online in html or pdf format. In other words, each access that is counted is the result of navigation or of download. While these data show general patterns there are limitations; for instance, based on the publisher's reporting system the overall access count of the Journal since 2013 varies from 108,766 - 121,242. Also, we have observed different trends in access rates that are moderated by a number of variables. For instance, some papers are proverbial sleepers: such papers have initially a low access count but readership picks up rapidly without tapering off; Other papers level off shortly after publishing. Respective examples are Rachel Harrison, Derek Flood, \& David Duce paper on mobile interaction whose accesses by month continue to grow; and the first JoIS editorial which tends to be accessed consistently, on average 130 a month. Likewise, as our readership grows, so do out accesses, which likely distorts absolute numbers. With these data properties and limitations in mind, and assuming random error of the reporting tools, we report percentages rather than absolute figures to indicate general reader interest. The access data depicted in Fig. 5 summarizes article accesses over a 30-day period from mid-February to mid-March 2016, based on 4,402 journal accesses.

According to the access data, it appears that frameworks and theory have make up the majority of access data, making up for nearly half of all journal accesses, $49 \%$. User modelling, empirical studies and case studies account for approximately $44 \%$ of all access while metrics and prototypes account for the remaining $7 \%$.

These data are provocative and suggest that JoIS readers prefer theoretical and framework papers, followed by traditional, data-driven research and engage less in scholarly work on method development, prototypes and metrics.

It seems reasonable to enrich the data reports with a more detailed analysis of JoIS contributions so far. Another viewpoint for the examination, "of what we publish" reviews the JoIS papers published so far (2013-2016) according to their grounding and main contribution, following psychological sciences and design thinking on one hand, and the TEAM approach on the other hand: Theory advancement, Empirical advancement, Applied advancement, Methodological advancements. Each paper is listed including its abstract in the Table 2.

Papers grounded in Psychological Sciences:

- Sachin Shah, J. Narasimha Teja, Samit Bhattacharya, [29]

- Christophe Deniaud, Vincent Honnet, Benoit Jeanne. Daniel Mestre, [30]

- Sandi Ljubic, Vlado Glavinic, \& Mihael Kukec, [31]

- Libby N Brockman, Dimitri A Christakis, Megan A Moreno, [32]

- Megan A Moreno, Lauren A Jelenchick, Rosalind Koff, Jens C Eickhoff,Natalie Goniu, Angela Davis, Henry N Young, Elizabeth D Cox, Dimitri A Christakis, [33]

\section{Design Science:}

- Tilo Mentler \& Michael Herczeg [34]

- Salim Chuifi \& Christoph Meinel, [35]

- Herre van Oostendorp \& Sonal Aggarwal, [36]

- Anke Dittmar, \& Laura Dardar, [37]

- Torsten Felzer, Ian MacKenzie, Stephan Rinderknecht, [38]

- Michael Heron, Vicki L Hanson, Ian Ricketts, [39]

- Rachel Harrison, Derek Flood, David Duce, [40] 
Table 2 JolS contributions 2013-2016

TITLE AUTHOR(S) \& APPROACH $\quad$ ABSTRACT

Reference no. KEYWORDS

Team cognition model based on mutual beliefs and mental subgrouping Journal of Interaction Science2016 4:1

\author{
Dipta Mahardhika \\ Taro Kanno \\ Kazuo Furuta \\ User Modelling \\ Empirical Study
}

Interactive cognitive artifacts for enhancing situation awareness of incident commanders in mass casualty incidents Journal of Interaction Science 2015 3:7

Cognitive artifacts

Situation awareness

Mass casualty incident command

Emergency medical services

Usability

Interaction design
Tilo Mentler

Michael Herczeg

Framework

Case study
In this research, an extension of a dyadic (pair) team cognition model is proposed to describe the cognition of a team with more than two persons. This model provides a comprehensive framework for analysing the cognitive aspects of team interactions, such as team situation awareness, team memory, and human-agent interac tions. One important aspect discussed in this research is a process called mental subgrouping. In a team with more than two persons, for each member to think of the other members as a single entity instead of several different individuals is natural. This behaviour is defined as mental subgrouping. By incorporating mental subgrouping into the mutual belief model, this research attempts to more accurately describe the cognition of a team from the perspective of both an out sider and the individual team members.

In mass casualty incidents, several members of Emergency Medical Services have to take actions in the field in order to cope with many injured or sick people. Incident commanders are responsible for managing operations, guiding rescue forces and applying resources appropriately under extraordinary circumstances. Data required for situation assessment, projection of developments and decision making are gathered by many different emergency physicians and paramedics. They are shared by numerous face-to-face talks, radio and phone calls as well as with the aid of paper-based forms and notepaper. While these tools and means of communication support flexible modes of operation, they often lead to deficient awareness of the situation. Due to temporal delays, poor handwriting and in complete data, information sharing in the field is hampered, delayed and faulty. Compared to established paper-based artifacts, interactive cognitive artifacts might improve the situations by exchanging and visualizing data in real-time. However, because of users' workload and working conditions, designing mobile computer-based tools and systems for this context of use is not only a technical but also a usability challenge. Based on the results of a two-year user-centered system design project in cooperation with German Emergency Medical Services, we discuss currently used and interactive cognitive artifacts for incident commanders. Challenges and approaches for successful user interface and interaction design are described and future work is outlined.

The role of affect and emotion in interactive system design is an active and recent research area. The aim is to make systems more responsive to user's needs and expectations. The first step towards affective interaction is to recognize user's emotional state. Literature contains many works on emotion recognition. In those works, facial muscle movement, gestures, postures and physiological signals were used for recognition. The methods are computation intensive and require extra hardware (e.g., sensors and wires). In this work, we propose a simpler model to predict the affective state of a touch screen user. The prediction is done based on the user's touch input, namely the finger strokes. We defined seven features based on the strokes. A linear combination of these features is proposed as the predictor, which can predict a user's affective state into one of the three states: positive (happy, excited and elated), negative (sad, anger, fear, disgust) and neutral (calm, relaxed and contented). The model alleviates the need for extra setup as well as extensive computation, making it suitable for implementation on mobile devices with limited resources. The model is developed and validated with empirical data involving 57 participants performing 7 touch input tasks. The validation study demonstrates a high prediction accuracy of $90.47 \%$. The proposed model and its empirical development and validation are described in this paper.

Organizations continue building virtual working teams (Teleworkers) to become more dynamic as part of their strategic innovation, with great benefits to individuals, business and society. However, during such transformations it is important to note that effective knowledge communication is particularly difficult in distributed environments as well as in non-interactive settings, because the interlocutors cannot
Patterns to explore cognitive preferences and potential collective intelligence empathy for processing knowledge in virtual settings Journal of Interaction Science 2015 3:5 Computer Science Telework Knowledge management
Salim Chujfi

Christoph Meine User Modeling

Framework

Case study 
Table 2 JolS contributions 2013-2016 (Continued)

Thinking styles

Learning styles

Self-government Collective intelligence

Collaborative work Cognitive patterns

Modeling and Supporting Web-Navigation Journal of Interaction Science 2015 3:3 Web-navigation Hyperlink Information scent Navigation support Cognitive models
Herre van Oostendorp Sonal Aggarwal User Modelling \& Empirical Research
Personal ecologies of calendar artifacts Journal of Interaction Science 2015 3:2 Calendars Calendar work Personal artifact Ecologies Appropriation Day-Reconstruction Method

use gestures or mimicry and have to adapt their expressions without receiving any feedback, which may affect the creation of tacit knowledge. Collective Intelligence appears to be an encouraging alternative for creating knowledge. However, in this scenario it faces an important goal to be achieved, as the degree of ability of two or more individuals increases with the need to overcome barriers through the aggregation of separately processed information, whereby all actors follow similar conditions to participate in the collective. Geographically distributed organizations have the great challenge of managing people's knowledge not only to keep operations running, but also to promote innovation within the organization in the creation of new knowledge. The management of knowledge from Collective Intelligence represents a big difference from traditional methods of information allocation, since managing Collective Intelligence poses new requirements. For instance, semantic analysis has to merge information, coming both from the content itself and the social/individual context, and in addition, the social dynamics that emerge online have to be taken into account. This study analyses how knowledge-based organizations working with decentralized staff may need to consider the cognitive styles and social behaviors of individuals participating in their programs to effectively manage knowledge in virtual settings. It also proposes assessment taxonomies to analyze online comportments at the levels of the individual and community, in order to successfully identify characteristics to help evaluate higher effectiveness of communication. We aim at modeling measurement patterns to identify effective ways of interaction of individuals, taking into consideration their cognitive and social behaviors.

Navigation within a website is an important factor for the success of a website. Faster and easy web-navigation leads to better usability and reduces cognitive load on the user. Several cognitive models exist that simulate the web-navigation process. In this paper we propose a new cognitive model - CoLiDeS++Pic (based on Comprehensionbased Linked model of Deliberate Search or CoLiDeS) that incorporates path adequacy and backtracking strategies. This model also takes into consideration the semantics of pictures. Firstly, we present here the results of an experiment in which we test the efficacy of support based on the new model CoLiDeS++Pic and multi-tasking under cognitively demanding situations. The results prove that the modelgenerated support is effective. Secondly, we also propose that in this way navigation behavior can be better modeled when compared to previous models. We verify this hypothesis by simulating the model on a mock-up website and comparing the results with a previous model CoLiDes+. Extending our previous work we demonstrate that the performance of the new model CoLiDeS++Pic is improved compared to the preceding model CoLiDeS+. We further discuss the challenges and advantages of automating navigation support using the proposed model.

Anke Dittmar Laura Dardar User Modelling Framework Casestudy
The use of calendars for work and personal activities has been widely investigated for decades and the term calendar work, coined by Palen (CHI 17-24,1999), refers to the many ways people employ and interact with calendars. Previous research has focused on calendar usage in specific domains or on the differences between paper and digital calendars. The current paper is positioned somewhat differently by exploring calendars as object in personal ecologies of calendar artifacts. In such personal calendar ecologies, the users, their tasks, their practices, and the calendar artifacts adapt and evolve together. In addition, individual users are typically engaged in various activities in specific contexts (realms) that are established and maintained by groups of people, supporting the overarching culture of these realms. As such, the web of common practices, activities and tasks, as well as the calendar artifacts shape the individual calendar work. To our knowledge, this article is the first study that investigates diverse personal ecologies of calendar artifacts. To this end we collected detailed user data with (a) exploratory interviews and (b) the DayReconstruction Method. The results indicate that the changing demands in daily life, the availability of new tools, and the participants' knowledge about the costs and benefits of their calendar work and about the consequences of potential failures influence their tendency to explore and possibly integrate new calendar artifacts and appear 
Table 2 JolS contributions 2013-2016 (Continued)

The concept of "presence" as a measure of ecological validity in driving simulators Journal of Interaction Science 2015 3:1 Driving simulator Spatial presence Attention Ecological validity Cognitive involvement
Christophe Deniaud Vincent Honnet Benoit Jeanne Daniel Mestre Methodology and Metric development
Predicting upper-bound text entry speeds for discrete-tilt-based input on smartphones Journal of Interaction Science 2014 2:3 Mobile Interaction

Text entry

Tilt interaction

Mobile devices Predictive models
Efficient computer operation for users with a neuromuscular disease with

OnScreenDualScribe

Journal of Interaction Science 2014, 2:2

Human-computer interaction

Universal Access

Keyboard replacement

Mouse emulator

Word prediction Ambiguous keyboards

Dysarthria

Neuromuscular diseases

implicated in the deliberate non-use of new technology. It appears that paper and digital calendar artifacts continue to co-exist. The results indicate an existing 'appointment culture' with a high demand of precisely scheduled episodes, and the importance of calendar artifacts for maintaining work and personal relationships in the light of the travel and new technologies for communication.

This pilot study aims to find a way to measure 'presence' as a proxy for ecological validity in driving simulators. The underlying assumption is that a person experiencing a strong sense of presence in the virtual environment will react as if it were real. We measure 'presence' through the 'attention' given to the driving task. We hypothesize that the greater the attention given to the primary driving task, the more the subject will experience spatial presence. 'Attention' was varied by adding a second task and oncoming traffic; we then analyzed behavioral measures of driving performance and subjective 'presence'. The main result is a lack of congruence between subjective and behavioral measures. Although behavioral differences were observed between the various experimental conditions, there was no significant difference in subjective measures of presence. One explanation for this result could be that in all experimental conditions the driving activity did not require high-level cognitive processes, and was instead based on bottom-up attentional processes. Many of the processes involved in driving seem to be automatic, and this study argues for the concomitant use of subjective measures (such as questionnaires) and objective measures to assess presence in driving simulators. Furthermore, the development of a sensitive measure of presence seems to require more challenging scenarios in terms of controlled attention, cognitive involvement and more specifically, the emotions induced by the media. Participants are clearly aware that they are not exposed to any physical danger when using the simulator and the problem of their motivation must be taken into consideration. Another major problem is to establish the extent to which they are absorbed in the simulated driving task. A significant challenge for future research is the emotional validity of driving.

Sandi Ljubic

Vlado Glavinic Mihael Kukec User Modeling Empirical study

Motion sensors integrated into contemporary smartphones allow the introduction of new mobile interaction paradigms, here including tilt-based input control in the mobile context. Namely, as opposed to existing implementations that typically apply continuous feedback on tilting, we define Pitch and Roll movement sequences that change the orientation of the mobile device as discrete-tilt input primitives. The respective commands are then used to manage text entry within three discrete-tilt-based methods thus introduced: keyboard bisection, single cursor, and quad cursor. Each method is based on the use of a particular QWERTY-based keyboard layout with related strategy for character input. We model upper-bound text entry speeds for the input methods, taking into account both movement aspects and language context. The movement model corresponds to both the tilt-based shortest path between two consequent characters, which is theoretically defined, and the time of discrete-tilt execution, which is obtained from user testing experiment we conducted. The linguistic model, comprising digraph statistics, is constructed basing on available English corpora. This modeling approach provides discrete-tilt-based text entry speed predictions representing efficiency rates for expert behavior, i.e. for optimal performance. The results obtained enable the evaluation of the proposed designs without need to test with real users, and can furthermore serve as a baseline for efficiency of text entry implementations that rely on discrete tilt.

Torsten Felzer Ian MacKenzie Stephan Rinderknecht Development and Testing of novel interaction artifact for disabled.

Case study

Prototype
We developed a tool based on a modified number pad to empower persons with certain diseases, in particular of neuromuscular origin to efficiently operate a computer and enter text. As the keypad lies securely in both hands, the system is ideal for someone who has motor problems using a full-size keyboard. The software offers various assistive techniques. For example, text entry is facilitated with the help of word prediction, and an ambiguous mode with word-level disambiguation allows text entry using the entire Latin alphabet with six keys.

In addition to describing the system, we analyze the ambiguous mode and the influence of dictionary size. Initial empirical results 
Table 2 JolS contributions 2013-2016 (Continued)

Friedreich's Ataxia

Friending adolescents on social networking websites: a feasible research too Journal of Interaction Science 2014 2:1 Adolescent social networking website Online friends over 12 months period Friending Internet Social media Research methods
Libby N Brockman Dimitri A Christakis Megan A Moreno Empirical Study Methodology
Associations between internet use and fitness among college students: an experience sampling approach

Journal of Interaction Science 2013 1:4
Megan A Moreno

Lauren A Jelenchick Rosalind Koff Jens C Eickhoff Natalie Goniu Angela Davis Henry N Young Elizabeth D Cox Dimitri A Christakis Empirical study
Open source and accessibility: advantages and limitations

Journal of Interaction Science 2013 1:2 Open source
Michael Heron

Vicki L Hanson lan Ricketts

Theory and Framework with the system, which is already in operation, indicate that it indeed represents a viable alternative by decreasing effort without increasing the time to operate a computer.

This journal article mainly differs from the related proceedings paper through an extended literature review and analyses regarding dictionary size.

Objective

Social networking sites (SNSs) are increasingly used for research. This paper reports on two studies examining the feasibility of friending adolescents on SNSs for research purposes. Methods Study 1 took place on http://www.MySpace.com where public profiles belonging to 18-year-old adolescents received a friend request from an unknown physician. Study 2 took place on http://www.Facebook.com where college freshmen from two US universities, enrolled in an ongoing research study, received a friend request from a known researcher's profile. Acceptance and retention rates of friend requests were calculated for both studies. Results

Study 1: 127 participants received a friend request; participants were 18 years-old, $62.2 \%$ male and 51.8\% Caucasian. 49.6\% accepted the friend request. After 9 months, $76 \%$ maintained the online friendship, $12.7 \%$ defriended the study profile and $11 \%$ deactivated their profile. Study 2: 338 participants received a friend request; participants were 18 years-old, $56.5 \%$ female and $75.1 \%$ Caucasian. $99.7 \%$ accepted the friend request. Over 12 months, 3.3\% defriended the study profile and $4.1 \%$ deactivated their profile. These actions were often temporary; the overall 12-month friendship retention rate was $96.1 \%$. Conclusion

Friending adolescents on SNSs is feasible and friending adolescents from a familiar profile may be more effective for maintaining online friendship with research participants over time.

Objective

Almost a third of college students are obese, placing them at risk for adult obesity and its complications. Internet use may be one factor contributing to college student obesity. The purpose of this study was to examine associations of college student internet use with physical activity and fitness.

Methods

Older adolescents between 18 and 23 years were recruited from a large university. Using experience sampling method, participants received 6 randomly-timed text message surveys for 7 days. Survey questions assessed whether they were currently online, for how long and current online activities. Participants also completed the International Physical Activity questionnaire and reported their body mass index. Multivariate models assessed the association of internet use with physical activity and fitness.

Results

Among 189 participants, the mean age was 18.9 (SD = 0.9), 58.8\% were female and most were Caucasian (90.5\%). Greater internet use was associated with fewer days per week of vigorous intensity exercise $(p<0.001)$. Participants who spent less than $1 \mathrm{~h} /$ day online reported a mean of 3.2 days per week of vigorous intensity exercise $(S D=2.0)$, those with 3 or more hours online daily reported $1.4(S D=2.1)$. Those who reported internet activities focused on academics reported increased days of vigorous intensity exercise compared to those who reported internet activity focused on social networking sites $(p<0.001)$. Conclusions

There were no significant associations between internet use time and BMI. Findings suggest that both online time and particular online activities may be associated with decreased vigorous physical activity. Future efforts should consider reframing internet use guidelines for this population around both time and activities.

In this paper we discuss the open source process as it relates to accessibility software. Open source is a development model that has shown considerable benefits in a number of application areas. However the nature of accessibility tools and the intended users of 
Table 2 JolS contributions 2013-2016 (Continued)

Human factors Accessibility

Usability

Inclusivity

Gamification
Usability of mobile applications: literature review and rationale for a new usability model Journal of Interaction Science 2013 1:1
Rachel Harrison

Derek Flood

David Duce

Theory and Framework such software products raise issues that must be addressed by the developer before users encounter the tools in real world contexts. In this paper we discuss the nature of the open source process, how it functions, and the motivations with regards to participation that developers self-report. We then explain the impact of these elements of the open source process as they relate to adaptive accessibility software. We use some specific examples of issues raised from the adoption of open source via a discussion of the ACCESS Framework, an accessibility engine designed to provide cross-platform accessibility support through plug-ins.

The usefulness of mobile devices has increased greatly in recent years allowing users to perform more tasks in a mobile context. This increase in usefulness has come at the expense of the usability of these devices in some contexts. We conducted a small review of mobile usability models and found that usability is usually measured in terms of three attributes; effectiveness, efficiency and satisfaction. Other attributes, such as cognitive load, tend to be overlooked in the usability models that are most prominent despite their likely impact on the success or failure of an application. To remedy this we introduces the PACMAD (People At the Centre of Mobile Application Development) usability model which was designed to address the limitations of existing usability models when applied to mobile devices. PACMAD brings together significant attributes from different usability models in order to create a more comprehensive model. None of the attributes that it includes are new, but the existing prominent usability models ignore one or more of them. This could lead to an incomplete usability evaluation. We performed a literature search to compile a collection of studies that evaluate mobile applications and then evaluated the studies using our model.
According to the TEAM approach each paper contributed as follows:

Theory advancements (in terms of models):

- Sachin Shah, J. Narasimha Teja, \& Samit Bhattacharya, [29] propose a simpler model to predict the affective state of a touch screen user as previously used, using finger strokes for prediction based on seven features that are combined predictor. A user's affective state is categorized as one of three emotional states. The model has been validated with empirical data, leading to a prediction accuracy of $90.47 \%$.

- Herre van Oostendorp \& Sonal Aggarwal, [36] propose a new cognitive model based on path adequacy and backtracking strategies, also recognizing the semantics of pictures. The effectiveness of support based on the new model could be proven in a multi-tasking experiment with cognitively demanding situations.

- Dipta Mahardhika, Taro Kanno, \& Kazuo Furuta, [41]. investigated team cognition and present empirical data as well as a comprehensive framework for analyzing the cognitive aspects of team interactions, such as team situation awareness, team memory, and human-agent interactions.
Empirical advancements:

- Sachin Shah, J. Narasimha Teja, \& Samit Bhattacharya, [29] - The prediction approach could be validated with empirical data involving 57 participants performing 7 touch input tasks. The validation study demonstrates a high prediction accuracy of $90.47 \%$.

- Libby N Brockman, Dimitri A Christakis, Megan A Moreno, [32] found out that making friendship for research with adolescents on social network sites is feasible, whereby friending adolescents from a familiar profile may be more effective for maintaining online friendships.

- Megan A Moreno, Lauren A Jelenchick, Rosalind Koff, Jens C Eickhoff, Natalie Goniu, Angela Davis, Henry N Young, Elizabeth D Cox, \& Dimitri A Christakis, [33] found out with respect to college students' obesity that there were no significant associations between internet use time and BMI. Their findings suggest that both online time and particular online activities may be associated with decreased vigorous physical activity.

- Dipta Mahardhika, Taro Kanno, \& Kazuo Furuta, [41] investigated team cognition and present empirical data as well as a comprehensive framework for analyzing the cognitive aspects of team interactions, such as team situation 


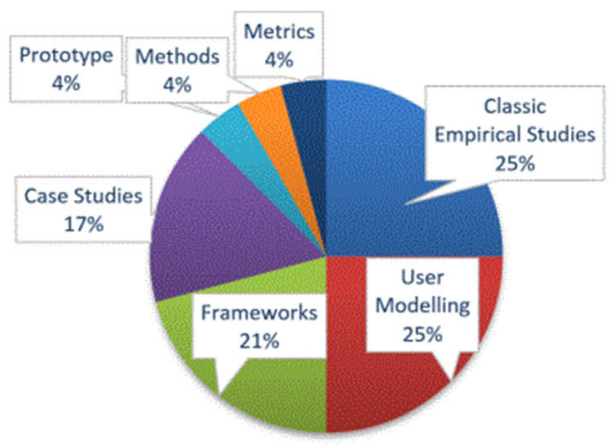

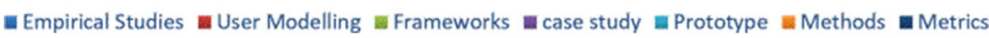

Fig. 4 Percentages of papers by TEAM \& Methodology

awareness, team memory, and human-agent interactions.

Applied advancement in terms of applying novel concepts or methods in the course of system development:

- Tilo Mentler \& Michael Herczeg [34] developed a novel interactive cognitive artifact for incident commanders increasing their situation awareness in mass casualty incidents.

- Salim Chujfi \& Christoph Meinel, [35] addressed virtual teams' work and could increase the effectiveness of their knowledge communication.

- Herre van Oostendorp \& Sonal Aggarwal, [36] could improve navigation within a website applying an extended cognitive model recognizing picture semantics.

- Anke Dittmar, \& Laura Dardar, [37] studied the use of calendars for work and personal purpose with respect to digitizing respective tools. It appears that paper and digital calendar artifacts continue to co-exist.
- Torsten Felzer, Ian MacKenzie, \& Stephan Rinderknecht, [38] developed a tool based on a modified number pad to assist persons with motor problems when providing input to technological artefacts.

- Michael Heron, Vicki L Hanson, Ian Ricketts, [39] redefined the development process of open source systems by relating it them to adaptive accessibility software and supporting user- and usage-relevant development issues.

Methodological advancements applying methods in new context or finding novel constituents for method development:

- Salim Chujfi \& Christoph Meinel, [35] - model patterns for measuring the effectiveness of interaction of individuals, taking into consideration their cognitive and social behaviors.

- Anke Dittmar, \& Laura Dardar, [37] use the Day-Reconstruction method to identify common

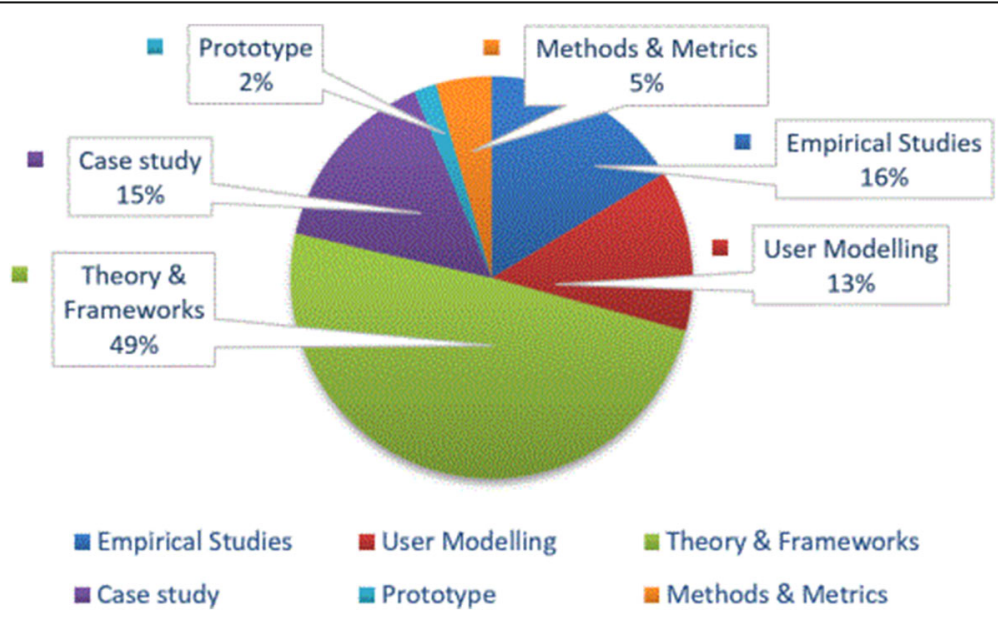

Fig. 5 Access Percentages by TEAM \& Methodology of papers published to date 
practices, activities and tasks related to calendar artefacts.

- Christophe Deniaud, Vincent Honnet, Benoit Jeanne. \& Daniel Mestre, [30] found a way to measure 'presence' as a proxy for ecological validity in driving simulators.

- Sandi Ljubic, Vlado Glavinic, \& Mihael Kukec, [31] provide a smartphone model for discrete tilt-based text entry speed prediction. It represents efficiency rates for optimal performance and could substitute user tests of smartphones.

- Libby N Brockman, Dimitri A Christakis, \& Megan A Moreno, [32] examined study designs for finding adolescent friends on social network sites for research purposes.

- Michael Heron, Vicki L Hanson, Ian Ricketts, [39] identified development topics to be raised by open-source developers before users encounter their development tools in real world contexts.

- Rachel Harrison, Derek Flood, \& David Duce, [40] designed a procedure overcoming limitations of existing usability models when applied to mobile devices through combining attributes from different usability models.

In summary, our empirically driven challenge, "the definition of what we do [as interaction scientists] is in the papers we publish" revealed interesting results. Based on the percentage data of contributions, JoIS embodies TEAM (theory, empirical data, applications, methodologies) and offers a diversity of methodologies and theoretical approaches. At the same time, framework papers in the theoretical category have attracted the majority of our readers' attention. One might argue that this interest is indicative of the relatively young age of our discipline and a reflection of our readers who seek new ways of thinking to solve interaction challenges and integrate theory with practice. While this interpretation should be evaluated in future editorials by investigating citations, references and related product development, the task at hand is to contextually define Interaction Science based on the journal's contribution and the definitions of interaction and science.

\section{What is interaction science?}

Interaction Science investigates interactional phenomena from different perspectives and disciplines. It provides transdisciplinary concepts, theories, and techniques for developing and evaluating contextual or adaptive sociotechnical systems. Researchers investigate articulation of human needs, the role and capabilities of developers, infrastructures, patterns of use and ambience, and socioeconomic issues. It aligns theories and conceptual findings with technology developments while empirically studying social, cognitive, motor, and emotional aspects of interactions.
Since Interaction Science is inclusive of a breadth of thematic areas that are not necessarily linked to a single research domain, Interaction Science should be linked to transdisciplinary approaches using scientific methodologies. Consider the relevancy of context of technological development, domain knowledge, such as in health care, becomes more and more the driver of applying design. For instance, smartphone data entries due to the networked nature of ambient technologies are not the same for health care apps as they are for personal contacts when synchronizing with web mail boxes; novel interface technologies, such as haptics, gestures, vision and brain computer interfaces require ontologies for design, as they deliver data to other networks. While the application domain remains the same, intertwining is stronger with emergent structure and behavior elements.

Models, in particular ontologies, play a crucial role in developing services or artefacts. One way to model in transdisciplinary research is to enrich existing models or specifications with contextual knowledge. For instance, for organizational design Le Clair et al. [42] expect a new generation of business process models within the next 5 years, designed from the outside replacing heavy packaged applications designed from inside-out, e.g., driven by functional deliveries. This design strategy still drive customer interaction today, but cannot keep up with the demands for change given by dynamic customer needs and the complexity of organizing work. Business process models are crucial for designing business information systems, as they (i) represent interaction among involved stakeholders (customers, domain specialists, producers) and (ii) serve as means of communication between the various stakeholder groups.

The quality of models plays an increasing role in adaptive environments [43], and need increasingly to be managed by stakeholders, e.g., when re-organizing their work. One major topic in Interaction Science research concerns the intelligibility of models, as models need to be communicated when being shared and reflected along organizational learning steps [44] - the communication skills of stakeholders will play a crucial role in transdisciplinary studies (cf. [45]). Interaction Science will touch on Human Resource Management, Human and Organizational Behavior, Organization Science, Education, and Social Media.

\section{Revised aims and scope}

In this section we discuss the aims and scope of Interaction Science from a conceptual and methodological perspective, which we define as follows:

Conceptually, inter-and cross-disciplinary research should be traversed by transdisciplinary research focusing on system-oriented and integrated study 
approaches; moreover, a system-of-system perspective on the subject of investigation could help to studying systems of high complexity, taking into account emergent behavior and interoperable system transformations.

Methodologically, we take into account and include multi-perspective studies and cognition and behaviororiented approaches relying on existing experiences and the diffusion of design thinking approaches when studying interaction.

\section{Towards transdisciplinary research}

A traditional approach to studying interaction relationships between humans and technology or between systems is by performing discipline-specific studies, focusing on dedicated aspects of interaction, such as psychologists working on social interaction topics, and computer scientists working on usable security or communication protocols. While such an approach will lead to specific insights into interaction processes, attaining a contextual or systemic understanding of the way interactions occur and the design of interactive processes operate, we need to go beyond this way of research. Although being a more challenging endeavor - researchers are likely to be enforced to leave the safety of their original territory, in particular moving beyond the comfort of their customary methods (cf. [46]). It is evident that the opportunity to explore and learn a new domain is likely to facilitate gaining an understanding of different perspectives and alternative ways of investigating phenomena and artefacts (cf. [47]).

Taking such a step allows for researching beyond traditional subject boundaries and appreciating scientific specialisms in a context ensuring that Interaction Science as a field of knowledge has a reality in the observed world. Working on such a context goes beyond interdisciplinary research as knowledge of several fields is not combined, but rather requires integrating and aligning (adjusting) concepts, theories, models and methods. Such mergers are common to transdisciplinary research [48]. Interaction Science requires an understanding of underlying knowledge fields plus their relationships when developing theories across disciplines (cf. [49]).

No doubt, an endeavor builds on taking multiple perspectives is likely to generate conflict and disagreement at the theoretical, methodological, possibly the empirical level, and certainly in applied contexts (cf. [50]). However, therein lies the strength of Interaction Science for it provides the platform that supports relevant transdisciplinary discourse for enabling the conflict resolution. Hence, differences and differentiation can be discussed on the high level, handling them at the meta-level of research approaches, where a common goal of an investigation can guide the integration or alignment processes.

It is the aforementioned set of characteristics qualifying research in Interaction Science as transdisciplinary endeavor. According to Pohl and Hadorn [51], transdisciplinary research is appropriate 'when knowledge about a societally relevant problem field is uncertain, when the concrete nature of problems is disputed, and when there is a great deal at stake for those concerned by problems and involved in dealing with them.' (ibid., p. 20) Interaction can be considered as a societally relevant phenomenon to generate certain knowledge about. Its concrete nature needs to be disputed the more technical systems are involved, as there is a great deal at stake for us, in particular thinking of reliability of information and communication access.

Transdisciplinary research aims to tackle topics in a way that researchers can grasp the complexity of issues while taking into account the diversity of life-world and scientific work. Method-wise it aims to link abstract and case-specific knowledge, when developing knowledge and practices for a common good (cf. [51]). It requires a systematic research process, composed of (i) problem identification and structuring, (ii) problem analysis, (iii) bringing results to fruition. For each of the steps researcher should follow several principles (cf. [51]):

- Reduce complexity by specifying the need for knowledge and identifying those involved, in particular in phase 1 of transdisciplinary research

- Achieve effectiveness through contextualization, e.g., identifying specific target groups

- Achieve integration through open encounters, e.g., through boundary objects, transfer of concepts, method bridges

- Develop reflexivity through recursiveness, limiting uncertainty and as means of targeted learning

In the following we briefly exemplify how some of these principles can be implemented when interaction is investigated through transdisciplinary research. Taking a System-of-Systems perspective allows reducing complexity while keeping the context of a research concern.

\section{Taking a system-of-systems perspective}

Once interactive distributed technologies are expected to reconfigure and adapt themselves according to changing environmental conditions and requirements, respective dedicated services need to be available for composition and orchestration (cf. [52]). Increasingly, such systems are composed of various operationally and managerially independent sub-systems, revealing semantic heterogeneity [53]. 
Typical examples are enterprise portals that aim to enable the integration and linking of information resources across different systems in real time [54]. On one hand, stakeholders want to use features or entire systems they are familiar with even in novel contexts. A typical example is Facebook as its functionality can be of use in private, work, and business contexts. On the other hand, different application contexts require different compositions of features or systems, such as a portal for market research differs from an accountant's workplace, referring to competitor or customer information, respectively, even if both provide analytics.

Rather than compiling such systems to inseparable entities, those systems are interconnected with respect to serving a common objective [55]. This particular class of systems is referred to as system-of-systems (SoS) (cf. [45]), and is increasingly investigated in the context of digitizing complex systems [56]. For instance, consider a supply network that integrates different systems, each managing a single transport modality, such as air cargo, sea freight, or road freight transport. Those systems are operated autonomously, but at the same time are all part of a bigger whole leading to emergent functionality and system behavior. For instance, the transport of goods by combining air cargo and sea freight may allow the optimization of delivery routes and therefore a decrease in delivery time and costs.

Another class of systems featuring emergent behavior are e-learning systems. Such systems couple content management and social media dynamically, depending on individual or collaborative learning processes (cf. [57]). Hereby, 'emergence occurs when interactions among objects at one level give rise to different types of objects at another level. More precisely, a phenomenon is emergent if it requires new categories to describe it which are not required to describe the behaviors of the underlying components.' ([58], p. 10) The provided added value, which cannot be attributed to a single system, is given through adjusting system properties for higher-level use, such as sharing contextsensitive annotations among learners for mutual feedback. The overall system therefore reveals some behavior that is more than the sum of its parts or component-systems (cf. [59]).

However, a topic deserving particular attention, as it goes beyond traditional research settings in interaction research, are communities whose members jointly create services and co-construct artifacts, as emotional, cognitive, organizational and technological skills are challenged when interacting in these social systems. Collaboration and cooperation are interactional phenomena that likely require transdisciplinary design due to their social and domain-specific nature at the same time.
Cooperatives have turned out beneficial for crisis and innovation management. A study by Smith St and Rothbaum [60] reveals that worker and producer cooperatives have not only benefits during times of economic crises, but also for large and small scale innovations. The latter 'are contributed by individual members. For worker cooperatives, observations that the workers make in the course of their daily work, whether in the context of building craft products, working on an assembly line, or service work, may be more likely to be mentioned, recorded, and built upon by the cooperative. In this way the cooperative can introduce improvements and new methods of production and organization with the more direct line of communication that their management structure facilitates. This is clearly a comparative advantage of cooperatives over conventional firms' (ibid., p.11), as long as organizations maintain some sort of exchange between the internal systems of the organization and the external world through bringing in new ideas, resources, and individuals [44].

\section{Conclusions}

In this contribution, we took a look at JoIS' albeit short, three-year history to learn and to reflect with the purpose to motivate, to inspire and to clarify our vision for the future. JoIS began as a journal dedicated to Interaction Science grounded in traditional laboratory empiricism and statistics to serve as a forum for researchers and practitioners who investigated the problem space of technology based interactions scientifically. We realize that the complex, and constantly changing problem space of Interaction Science requires more than lab experiments. Indeed, we encourage creative problem solvers and innovators in design sciences and design engineering to contribute and embrace the scope and the challenge of understanding of sociotechnical systems.

Establishing Interaction Science as human science we want to employ the best of social and cognitive sciences applied to engineering developments. We still believe that rigorous research methodology is the marlin spike that can unravel the convoluted knot of interactions between humans and the technologies that they have created, and progress towards stakeholder-driven development. Our goal is to attract cross-disciplinary research and inspire theory-grounded scientific investigations of human interactions with modern technologies, including their potential for bringing about change, their limitations, their benefits, their consequences and their broader impact.

Hence, we ask that our contributors remain committed to the TEAM approach: Theory advancement, Empirical advancement, Applied advancement, Methodological advancements. We believe that the JoIS' authorship and audience will benefit from this contextual understanding and the resulting transdisciplinary results. 


\section{Endnotes}

${ }^{1}$ http://www.journalofinteractionscience.com/content/ $1 / 1 / 3$

${ }^{2}$ http://www.merriam-webster.com/dictionary/science ${ }^{3}$ http://www.merriam-webster.com/dictionary/ epistemology

${ }^{4}$ http://www.britannica.com/topic/empiricism

${ }^{5}$ http://www.britannica.com/topic/rationalism

${ }^{6}$ For food for thought http://www.pbs.org/wgbh/nova/ blogs/physics/2015/02/falsifiability/

${ }^{7}$ http://www.oxforddictionaries.com/us/definition/ american_english/case-study

\section{Authors' contributions}

Each author contributed 50\% to the manuscript. Both authors read and approved the final manuscript.

\section{Competing interests}

The authors declare that they have no competing interests.

\section{Author details}

${ }^{1}$ Florida Institute of Technology "150 W. University Blvd, Melbourne, FL 32901, USA. '2University of Linz, Altenbergerstraße 69, 4040 Linz, Austria.

\section{Received: 5 June 2016 Accepted: 8 November 2016}

\section{Published online: 12 December 2016}

\section{References}

1. Howes, A., Cowan, B. R., Janssen, C. P., Cox, A. L., Chaims, P., Hornof, A. J., \& Pirolli, P. (2014). Interaction science SIG: overoming challenges, CHI'14 Extended Abstracts on Human Factors in Computing Systems (pp. 1127-1130). New York: ACM.

2. Rugman, A. (2012). The end of globalization. New York: Random House.

3. Roth, S. (2013). The Fairly Good Economy: Testing the Economization of Society Hypothesis against a Google Ngram View of Trends in Functional Differentiation (1800-2000). The Journal of Applied Business Research, 29(5), 1495-1500.

4. Van Dijck, J. (2013). The culture of connectivity: A critical history of social media. New York: Oxford University Press.

5. Anderies, J. M. (2015). Understanding the dynamics of sustainable socialecological systems: human behavior, institutions, and regulatory feedback networks. Bulletin of Mathematical Biology, 77(2), 259-280

6. Chaffin, B. C., \& Gunderson, L. H. (2016). Emergence, institutionalization and renewal: Rhythms of adaptive governance in complex social-ecological systems. Journal of Environmental Management, 165, 81-87.

7. Giddens, A. (1990). The Consequences of Modernity. Stanford, CA: Stanford University Press.

8. Maingret, B., Le Mouël, F., Ponge, J., Stouls, N., Cao, J., \& Loiseau, Y. (2015). Towards a Decoupled Context-Oriented Programming Language for the Internet of Things. In Proceedings of the 7th International Workshop on Context-Oriented Programming (p. 7). ACM

9. Richardson, C. (2014). Microservices: Decomposing Applications for Deployability and Scalability, http://www.infoq.com/articles/microservicesintro, download 7.9.2015

10. Fleischmann, A., Schmidt, W., Stary, C. H., Obermeier, S. T., \& Börger, E. (2012). Subject-oriented Business Process Management. Berlin: Springer.

11. Uckelmann, D., Harrison, M., \& Michahelles, F. (2011). An architectural approach towards the future internet of things (pp. 1-24). Berlin Heidelberg: Architecting the internet of things. Springer.

12. Kim, J., \& Lee, J. W. (2014). OpenloT: An open service framework for the Internet of Things. In, IEEE World Forum on Internet of Things (pp. 89-93). IEEE.

13. Bandyopadhyay, A., Gualtieri, T. P., \& Bose, S. (2015). Global Engineering and Additive Manufacturing. Additive Manufacturing, 1. Boca Raton: CRC Press.

14. Nolden, M., Zelzer, S., Seitel, A., Wald, D., Müller, M., Franz, A. M., \& Wolf, I. (2013). The medical imaging interaction toolkit: challenges and advances. International Journal of Computer Assisted Radiology and Surgery, 8(4), 607-620.

15. Simon, H. A. (1996). The sciences of the artificial (3rd ed.). Cambridge, MA, USA: MIT Press.
16. Gomm, R., Hammersley, M., \& Foster, P. (2000). Case Study Methods. London: Sage

17. Harvey, D. L. (2009). Complexity and Case. In D. Byrne \& C. C. Ragin (Eds.), Sage Handbook of Case-Based Methods (London: Sage, Vol. Ch 1, pp. 15-39).

18. Mjøset, L. (2009). The contextualist approach to social science methodology. In D. Byrne \& C. C. Ragin (Eds.), Sage handbook of case-based methods (London: Sage, Vol. Ch 2, pp. 39-68).

19. Clifford Geertz. (1973). The Interpretation of Cultures. Basic Books, Inc

20. van Aken, J. E. (1994). De bedrijfskunde als ontwerpwetenschap, De regulatieve en reflectieve cyclus. (The business as a design science). The regulatory and reflective cycle Bedrijfskunde, 66(1), 16-26.

21. van Strien, J., \& Praktijk als wetenschap. (1986). Methodologie van het sociaalwetenschappelijk handelen (Practice and science. Methodology of scientific acting in social science). Assen: Van Gorcum.

22. De Groot, A. (1969). Methodology: Foundations of Inference and Research in the Behavioral Sciences. Belgium: Mouton \& Co.

23. McKay, J., Marshall, P., \& Hirschheim, R. (2012). The design construct in information systems design science. Journal of Information Technology 27(2), 125-139.

24. Germonprez, M., Hovorka, D., \& Gal, U. (2011). Secondary design: A case of behavioral design science -research. Journal of the Association for Information Systems, 12(10), 662-683.

25. Patrick, H.A., Kumar, V.R. (2012) Managing Workplace Diversity: Issues and Challenges, SAGE Open, 1-15 (2012). doi: 10.1177/2158244012444615, http:// sgo.sagepub.com, download 1.9.2015

26. Senge, P. M. (1990). The fifth discipline: The art and practice of the learning organization. New York: Currency Doubleday.

27. Wieringa, R. J. (2014). Design science methodology for information systems and software engineering. Springer.

28. Reinecke, K., \& Bernstein, A. (2013). Knowing what a user likes: A design science approach to interfaces that automatically adapt to culture. MIS Quarterly, 37(2), 427-453.

29. Sachin, S., Narasimha Teja, J., \& Bhattacharya, S. (2015). Towards affective touch interaction:predicting mobile user emotion from finger strokes. Journal of the Association for Information Systems, 3, 6.

30. Deniaud, C., Honnet, V., Jeanne, B., \& Daniel, M. (2015). The concept of 'presence* as a measure of ecological validity in driving simulators. Journal of the Association for Information Systems, 3, 1.

31. Ljubic, S., Glavinic, V., \& Kukec, M. (2014). Predicting upper-bound text entry speeds for discrete-tilt-based input on smartphones. Journal of the Association for Information Systems, 2, 3.

32. Brockman, L. N., Christakis, D. A., \& Moreno, M. A. (2014). Friending adolescents on social networking websites: a feasible research tool. Journal of the Association for Information Systems, 2, 1.

33. Moreno, M. A., Jelenchick, L. A., Rosalind, K., Eickhof, J. C., Natalie, G., Angela, D., Young, H. N., Cox, E. D., \& Christakis, D. A. (2013). Associations between internet use and fitness among college students an experience sampling research. Journal of the Association for Information Systems, 1, 4

34. Mentler, T., \& Herczeg, M. (2015). Interactive cognitive artifacts enhancing situation awareness of incident commanders in mass causalty incidents. Journal of the Association for Information Systems, 3, 7.

35. Chujfi, S., \& Meinel, C. (2015). Patterns to explore cognitive preferences and potential collective intelligence empathy for processing knowledge in virtual settings. Journal of the Association for Information Systems, 3, 5 .

36. van Oostendorp, H., \& Aggarwal, S. (2015). Modeling and supporting web navigation. Journal of the Association for Information Systems, 3, 3.

37. Dittmar, A., \& Dardar, L. (2015). Personal ecologies of calendar artifacts. Journal of the Association for Information Systems, 3, 2.

38. Felzer, T., MacKenzie, I.S. \& Rinderknecht, S. J (2014). Efficient computer operation for users with a neuromuscular disease with OnScreenDualScribe. Interact Sci. doi:10.1186/s40166-014-0002-7.

39. Heron, M., Hanson, V. L., \& lan, R. (2013). Open source and accessiblity: advantages and limitations. Journal of the Association for Information Systems, 1, 2.

40. Harrison, R., Flood, D., \& Duce, D. (2013). Usability of mobile applications: literature review and rationale for a new usability model. Journal of the Association for Information Systems, 1, 1

41. Mahardhika, D., Kanno, T., \& Furuta, K. (2016). Team cognition model based on mutual beliefs and mental subgrouping. Journal of the Association for Information Systems, 4,1.

42. Le Clair, C., Moore, C., Peters, A., Miers, D., \& Fowler-Cornfeld, E. (2012). Stuck in Cement: When Packaged Apps Create Barriers to Innovation. Cambridge, MA: Forrester Research. 
43. Claes, J., Vanderfeesten, I., Reijers, H. A., Pinggera, J., Weidlich, M., Zugal, S., Fahland, D., Weber, B., Mendling, J., \& Poels, G. (2012). Tying process model quality to the modeling process: the impact of structuring, movement, and speed (pp. 33-48). Springer, Berlin: Business Process Management.

44. Frishammar, J., Lichtenthaler, U., \& Richtnér, A. (2013). Managing process development: key issues and dimensions in the front end. $R \& D$ Management, 43(3), 213-226.

45. Pew, R. W., \& Mavor, A. S. (2007). Human-system integration in the system development process: A new look. Washington, DC: National Academy Press. http://books.nap.edu/catalog.php?record_id=11893, checked August 2016.

46. Feyerabend, P. (1993). Against method (3rd ed.). London: Verso.

47. Dalcher, D. (2006). Consilience for universal design: the emergence of a third culture. Universal Access in the Information Society, 5(3), 253-268.

48. Pohl, C., van Kerkhoff, L., Hirsch Hadorn, G., \& Bammer, G. (2008). Integration. In G. Hirsch Hadorn, H. Hoffmann-Riem, S. Biber-Klemm, et al. (Eds.) Handbook of Transdisciplinary Research (pp. 411-424). Bern: Springer.

49. Russell, A. W., Wickson, F., \& Carew, A. L. (2008). Transdisciplinarity: Context, contradictions and capacity. Futures, 40(5), 460-472.

50. Balsiger, J. (2015). Transdisciplinarity in the class room? Simulating the co-production of sustainability knowledge. Futures, 65, 185-194.

51. Pohl, C., \& Hadorn, G. H. (2007). Principles for designing transdisciplinary research. Munich: Oekom.

52. Kramer, J., Magee, J. (2007). Self-managed systems: an architectural challenge. In Future of Software Engineering, 2007 (pp. 259-268). FOSE'07, IEEE

53. Foster, S. Miyazawa, A. Woodcock, J., Cavalcanti, A., Fitzgerald, J., Larsen, P.G. (2014). An approach for managing semantic heterogeneity in systems of systems engineering, In System of Systems Engineering (SOSE) (pp. 113-118) 9th International Conference on, IEEE.

54. Raol, J. M., Koong, K. S., Liu, L. C., \& Yu, S. (2003). An identification and classification of enterprise portal functions and features. Industrial Management Data Systems, 103(9), 693-702. doi:10.1108/ 02635570310506115. URL http://dx.doi.org/10.1108/02635570310506115.

55. Jamshidi, M. (2010). Systems of Systems Engineering: Principles and Applications. Boca Raton: CRC Press.

56. Weichhart, G., Molina, A., Chen, D., Whitman, D. E., \& Vernadat, F. (2016). Challenges and current developments for sensing, smart and sustainable enterprise systems. Computers in Industry, 79, 34-46.

57. Pelet, J.-E., Pratt, M. A., \& Fauvy, S. (2015). Moocs and the integration of social media and curation tools in e-learnin (pp. 43-53). Learning Technology for Education in Cloud: Springer.

58. Gilbert, R. (1995) Emergence, (c) Robert Gilbert

59. Khan, B.H. (2015). Introduction to e-learning, International Handbook of E-Learning Volume 1: Theoretical Perspectives and Research, p. 1-40.

60. Smith St, C., \& Rothbaum, J. (2013). Cooperatives in a Global Economy: Key Economic Issues, Recent Trends, and Potential for Improvement (IZA Policy Paper No. 68, p. 26). Bonn, Germany: Institute for the Study of Labor.

\section{Submit your manuscript to a SpringerOpen ${ }^{\circ}$ journal and benefit from:}

- Convenient online submission

- Rigorous peer review

- Immediate publication on acceptance

- Open access: articles freely available online

- High visibility within the field

Retaining the copyright to your article 